\title{
Instrumento de medición: proceso de lectoescritura en estudiantes de básica media
}

\section{Measuring instrument: literacy process in elementary school students}

1 Elena del Rocío Rosero Morales https://orcid.org/0000-0001-7004-3207

Universidad Técnica de Ambato, Facultad de Ciencias Humanas y de la Educación, Carrera de Educación Inicial. Ambato, Ecuador.

elenadroserom@uta.edu.ec

2 Silvia Beatriz Acosta Bones iD https://orcid.org/0000-0002-5874-5764 Universidad Técnica de Ambato, Facultad de Ciencias de la Educación, Carrera de Educación Inicial. Ambato, Ecuador. silviabacostab@uta.edu.ec

3 Milena Aracely Estupiñán Guamani https://orcid.org/0000-0002-5874-5764 Universidad Técnica de Ambato, Facultad de Ciencias Humanas y de la Educación, Carrera de Educación Inicial. Ambato, Ecuador, ma.estupinan@uta.edu.ec

4 Jeanneth Caroline Galarza Galarza https://orcid.org/0000-0002-2837-5651

Universidad Técnica de Ambato, Facultad de Ciencias Humanas y de la Educación, Carrera de Educación Inicial-Educación Básica. Ambato, Ecuador, Doctorando en Ciencias de la Educación Universidad Nacional de Trujillo, Perú. jeannethcgalarzag@uta.edu.ec

Artículo de Investigación Científica y Tecnológica Enviado: 24/12/2021

Revisado: 29/12/2021

Aceptado: $12 / 01 / 2022$

Publicado:08/03/2023

DOI: $\underline{\text { https://doi.org/10.33262/concienciadigital.v6i1.4.1996 }}$

Cítese:

Rosero Morales , E. del R., Acosta Bones, S. B., Estupiñán Guamani , M. A., \& Galarza Galarza, J. C. (2023). Instrumento de medición: proceso de lectoescritura en estudiantes de básica media. ConcienciaDigital, 6(1.4), 251-265. https://doi.org/10.33262/concienciadigital.v6i1.4.1996

CONCIENCIA DIGITAL, es una Revista Multidisciplinar, Trimestral, que se publicará en soporte electrónico tiene como misión contribuir a la formación de profesionales competentes con visión humanística y crítica que sean capaces de exponer sus resultados investigativos y científicos en la misma medida que se promueva mediante su intervención cambios positivos en la sociedad. https://concienciadigital.org

La revista es editada por la Editorial Ciencia Digital (Editorial de prestigio registrada en la Cámara Ecuatoriana de Libro con No de Afiliación 663) www.celibro.org.ec 


\section{Palabras}

claves:

lectoescritura,

lectura, escritura, Básica

Media

\section{Keywords:}

literacy, reading, writing, elementary school

\section{Resumen}

El tema se encuentra enfocado desde la necesidad de las Unidades Educativas donde se evidencian problemas de lectura deficiente tanto fonológica como comprensiva, mostrando errores en la interpretación del texto, la escritura que presenta falta de direccionalidad en sus rasgos, letras ilegibles, confusión en letras por forma, orientación y direccionalidad en los trazos de las mismas, faltas de ortografía, inadecuado uso de mayúsculas y minúsculas, todas estas premisas han ocasionado dificultades para que los estudiantes de Básica Media logren escribir usando reglas gramaticales adecuadas, dificultando así el rendimiento académico. Por otra parte, los estudiantes muestran desmotivación en las clases, pues el desinterés en la lectura hace que se limiten ampliar conocimientos que solo la lectura comprensiva logra en sus capacidades cognitivas. El artículo se fundamenta en instrumentos de medición que facilita al docente conocer de forma diagnostica el proceso de lectoescritura en los estudiantes, tomando en consideración el proceso, niveles y subniveles de este. Las fichas de observación construidas fueron validadas en el programa SPSS, donde demuestran que los tres instrumentos son un medio confiable en la recolección de la información para el docente como instrumento de medición que ayude a determinar el proceso de lectoescritura en estudiantes de básica media.

\section{Abstract}

The subject is focused on the need for Educational Units where poor phonological and comprehensive reading problems are evident, showing errors in the interpretation of the text, writing that presents lack of directionality in its features, illegible letters, confusion in letters due to form, orientation and directionality in the lines of the same, misspellings, inappropriate use of capital letters and small letters, all these premises have caused difficulties for the students of Basic Middle to be able to write using appropriate grammatical rules, thus hindering academic performance. On the other hand, the students show demotivation in the classes, since the lack of interest in reading makes them limit themselves to expand knowledge that only comprehensive reading achieves in their cognitive abilities. The article is based on measurement instruments that facilitate the teacher to know in a diagnostic way the literacy process in students, taking into consideration the process, levels and sublevels of the 
same. The observation files constructed were validated in the SPSS program, where they show that the three instruments are a reliable means of collecting information for the teacher as a measuring instrument that helps determine the literacy process in middle school students.

\section{Introducción}

La educación debe estar unida a la innovación con el fin de incluir nuevas metodologías para desarrollar las macro destrezas de lectoescritura, partiendo desde un estudio contextual desde España (Tamayo, 2017) determina la prevalencia de alumnos con dificultades en la lectoescritura, y la importancia del diagnóstico temprano para redirigir el proceso de enseñanza de lectoescritura donde se debe romper los esquemas para un trabajo multidisciplinario de escuela y padres de familia, donde se busca alternativas que ayuden a superar falencias en el proceso de enseñanza aprendizaje, bajo un contexto meso en Latinoamérica existe un alto nivel de problemas lectoescritores que afecta el rendimiento académico de los estudiantes por lo que (American Institutes for Research [AIR], 2019), hace referencia que en América Latina las deficiencias asociadas a la lectoescritura son altas siendo consecuencia de un inadecuado proceso de adquisición de destrezas durante la escolaridad evidenciando una mala praxis por lo que es importante formular nuevas estrategias que ayuden a superar estas limitaciones en cuanto a la lectura y escritura, en el contexto nacional presenta un rango de vacíos en el proceso de lectoescritura es así que luego de determinar problemáticas que tienen los estudiantes en el ámbito escolar propone estrategias lúdicas enfocadas al desarrollo de habilidades linguiísticas donde la estimulación a la lectoescritura parte de adquirir gusto a la lectura, producir textos que tengan un lenguaje rico en significado, con el fin de enriquecer las capacidades para producir textos y comprender logrando una reflexión activa es decir formar infantes con pensamiento crítico que logren aprendizajes significativos.

Cabe recalcar que la actualización de conocimientos de los docentes y personal que trabaja en el nivel de enseñanza en edades tempranas es de vital importancia, pues el perfil profesional ayudará que la labor educativa sea acorde a las necesidades del infante, el manejo de la etapa del aprestamiento del educador inicial es importante ya que el educador y el padre visualizan la dificultad que tienen los niños al intentar leer y escribir antes de los 6 años, obviamente por la edad, aún no están preparados y no han alcanzado las habilidades necesarias para este aprendizaje, pero la curiosidad hace que con esfuerzo la lectura global sea efectiva, considerando que la educación es estándar y no individual (Lema, 2019).

El aprestamiento en la educación preescolar cuyo objetivo se centra en la incidencia de las técnicas lúdicas en la lectoescritura, donde el juego como estrategia es fundamental 
en el aprendizaje; la generación del ambiente adecuado, la construcción del conocimiento y la participación activa del niño sin temor a la lectura como eje primordial para el primer escenario de la escritura (Toledo et al., 2018), y cultivar en los niños la capacidad para hablar, escuchar, leer y escribir correctamente.

La lectoescritura es el proceso donde el niño desarrolla habilidades de leer y escribir, son destrezas que se adquieren a partir de la segunda infancia, es decir desde inicios de la escolaridad de 3 a 6 años, a esta edad el docente de educación inicial logra incursionar en esta habilidad, dando un realce a la necesidad de afianzar las destrezas motrices, lateralidad, esquema corporal percepción a través del movimiento, que permita madurar las funciones de la mente y organizar su esquema corporal como punto de partida para el inicio del proceso de lectoescritura (Avila, 2017).

La experiencia de la lectoescritura en el aula muestra que para que el aprendizaje de manera óptima se debe considerar las estrategias que el docente use para facilitar el desempeño de los estudiantes, en esencia el fortalecer el proceso de enseñanza, para promover un aumento en los resultados de aprendizaje (Begoña et al., 2018). En general, las estrategias tradicionales se abandonan para innovar debido a la falta de resultados positivos, por lo tanto, es fundamental buscar nuevas alternativas a procesos viables. Así, el proceso de enseñanza-aprendizaje de la lectura es el punto de partida y uno de los principales contenidos de la educación inicial, que reviste una importancia primordial en la vida del infante. Aprender a leer o leer con dificultad tiene un impacto negativo, no solo en el aprendizaje en la escuela, sino también en el desarrollo emocional, psicológico y cognitivo, ya que impide que los niños adquieran los conocimientos que deben lograr acorde a su edad (Martínez et al, 2016).

La producción y comprensión de textos juegan un papel importante, y la enseñanza de parte de los docentes proporciona una síntesis del texto desde la educación inicial además del procesamiento y desarrollo de la estructura de la palabra escrita, así como el desempeño de la palabra escrita, el análisis de la ortografía y formación de oraciones, y la evaluación de la calidad del texto (Bañales et al., 2017), es de importancia para dar el valor a la lectura y la escritura como son dos habilidades fundamentales en la vida, que deben desarrollarse desde una edad temprana, para que los niños se acostumbren a ellas. Muchos factores influyen en este proceso: conocimientos previos, dificultades de aprendizaje, métodos de enseñanza, etc. (Rodríguez, 2015).

Al hablar de los problemas de lectoescritura Jiménez (2012), hace referencia que son evidenciados en la labor docente en determinados alumnos en la educación inicial, que en muchas de las veces sin tener necesidades educativas especiales asociadas o no a una discapacidad son cada vez van en aumento como la dislexia (problema de aprendizaje especifico en la escritura, al aprender las letras), dislalia (problema de aprendizaje especifico en la pronunciación de las letras), disgrafia (alteración de la escritura especifica 
unida a trastornos perceptivos-motores) y disortografia (escritura con muchas faltas ortográficas) son problemas de aprendizaje asociados al proceso de lectoescritura.

Es usual el evidenciar como los estudiantes de básica media correspondiente a $5 .^{\circ}, 6^{\circ}$. y 7..$^{\circ}$ grados de educación general básica, que significa los terceros infantes de 9 a 11 años; presentan lecturas sin comprensión, donde se plasma en papeles escritos de textos solo el copiar textos sin reflexión de su trabajo y no se lleva a la práctica procesos de lectura como de escritura que generen un desarrollo de habilidades lectoras ni de escritura (Páez, 2018).

Los alumnos de básica media presentan problemas específicos como falta de comprensión lectora, caligrafía ilegible, confusión de letras que en sonido se parecen, la falta también se observa al no asumir la responsabilidad y concienciar sobre lo importante de la lectoescritura de 9 a 11 años, asumiendo que a esta edad ya conocen y manejan la lectoescritura, además en el aspecto educativo los docentes tienen una estrategia inadecuada para llegar a los estudiantes y lograr resultados efectivos. Para tener un cierto impacto en su educación se deberá considerar al entorno familiar y escolar y encontrar causas verificables para buscar estrategias positivas para apoyar la educación en el aula dentro del proceso de aprendizaje; creando un hábito de tolerancia y comprensión para quienes presentan estas dificultades.

\section{Proceso de lectoescritura}

Conociendo a la lectoescritura como el proceso por el cual un alumno aprende el procedimiento de leer y entender un texto para lograr escribir usando un alfabeto, desde los primeros años de educación inicial hasta el dominio de este (Rosalía, 2016), desintegraremos cada uno de los conceptos que forman la lectoescritura.

\section{Proceso de lectura}

Menciona Meneses (2015), que los factores que inciden en el proceso de adquisición de la lectura, cuyas fases desarrollan habilidades cognitivas fundamentales en su maduración intelectual siendo: logográfica, alfabética y ortográfica, fluida expresiva

Logográfica: Son las características graficas o visuales del texto con el fin de leer las palabras, relacionando una señal grafica con el mensaje, lo cual será almacenado en la memoria posteriormente, siendo el punto de partida para lograr una construcción adecuada y eficaz del proceso;

Alfabética: Los estudiantes requieren conocer los sonidos y nombres de cada letra del alfabeto, logrando codificar fonológicamente letras, pronunciando correctamente su sonido para luego reconocer silabas y palabras. 
Ortográfica: El estudiante ya procesa secuencias de letras, leyendo las palabras y relacionando con imágenes para formar frases que tengan sentido.

Fluida expresiva: Es el resultado de las anteriores considerando el dominio de lectura manejando la puntuación, expresión y el contexto. Implica el acceso directo a la semántica y un control automático del proceso de decodificación

El proceso mencionado trabajado correctamente desde inicios de la escolaridad y en el trascurso de esta fomentaran estructuras cognitivas activas que ayudarán en la maduración intelectual y mejoraran el proceso de enseñanza aprendizaje.

Para Farrach (2016), menciona tres etapas para el proceso de lectura que ayudaran a una mayor comprensión y asimilación de conceptos siendo: prelectura, iniciación a la lectura y la lectura comprensiva.

Prelectura: En la primera etapa se trabaja con ejercicios que desarrollen la memoria visual, auditiva, lógica y la atención, siendo estos, por ejemplo, determinar un gráfico, escuchando el nombre, describir su estructura y memorizar el significado para interiorizar mediante formas, colores, trabajando su memoria.

Iniciación a la lectura: Consiste en afianzar y desarrollar la lectura mediante la identificación, el reconocimiento de palabras, con el fin de facilitar la comprensión de los textos, siendo esta etapa la más esencial para lograr un aprendizaje significativo

Lectura comprensiva: Es el proceso lector propiamente dicho, donde juega un papel importante los intereses de los estudiantes para lograr interés y agrado, motivando a la lectura para luego afianzar con otros tipos de textos según su formación.

Según Gómez et al. (2016) mencionan el método ecléctico el más eficaz para utilizar en la enseñanza de la lectura siendo mixto debido a que se dan a los estudiantes ejercicios preparatorios iniciales para promover habilidades de organización espacial, coordinación visomotora, discriminación auditiva, atención, memoria y lenguaje oral, por ejemplo, al mostrar un dibujo donde ellos escuchen de que se trata, reproduciendo su nombre a más de describirlo, identificando características, para luego presentar los sonidos de las letras, el nombre y el símbolo escrito, reproduciendo las mismas, una vez ya afianzado los conocimientos se pasa a que tomen dictados, creen palabras, visualizar las formas de las letras, crear nuevas palabras y por ultimo entender la relación oral escrita.

\section{Proceso de escritura}

La didáctica textual o Didactext es un proceso que establece cuatro fases para la escritura:

1. El acceso al conocimiento o activación mental de la información que posibilita la estimulación de imágenes, lugares, acciones, acontecimientos desde dentro 
proporcionando un cierto control de contenidos semánticos que luego derivan en una producción textual;

2. La planificación siendo una estrategia de organización, estableciendo objetivos que orienten el esquema del proceso dotando de significado propio al texto;

3. La producción textual que relacione normas de organización literal internas como externas para generar conceptos utilices;

4. La corrección del texto como retroalimentación identificando los errores y encaminando los procesos hacia el texto final con su edición y presentación oral (Riera et al., 2015).

Pre-requisitos para el aprendizaje de la lectura y la escritura

Según Núñez \& Santamarina (2014), manifiestan los siguientes prerrequisitos como factores claves que ayudaran al desarrollo académico y personal del niño durante su crecimiento;

1. Desarrollo de la motricidad: Todas las habilidades motrices y de orientación espacial y temporal son fundamentales para que el estudiante logre un adecuado inicio del aprendizaje de la lectura y la escritura.

2. Procesos cognitivos: Son diversos conjuntos necesarios y que se debe dominar para lograr que los estudiantes puedan escribir y leer, sin dejar de lado que también dependerá del desarrollo cognitivo del mismo alumno en el momento de iniciar dicho aprendizaje.

3. Habilidades o destrezas orales de la lengua: El ser humano al momento de nacer se encuentra rodeado de sus seres queridos, utilizando el lenguaje oral para manifestarse y poder comunicarse, ayudando a que los bebes asimilen este tipo de comunicación y logren desarrollando esta habilidad, siendo relevante en la etapa de la Educación Inicial, concibiendo como el instrumento primordial de aprendizaje, de regulación de la conducta y de manifestación de vivencias, sentimientos, ideas, emociones, etcétera.

4. Conciencia fonológica: las habilidades metalingüísticas del lenguaje: es la capacidad para reflexionar y manipular los diversos compendios que constituyen el lenguaje (fonemas, palabras, estructura de las proposiciones) logrando reflexionar sobre su propio conocimiento

Al desarrollar las cuatro habilidades fundamentales como son el hablar, escuchar, leer y escribir, resultantes de la relación del código oral y escrito con las capacidades expresivas y comprensivas, que intervienen en el dominio de la lengua y que permiten que el individuo se comunique con claridad para expresar lo que piensa y siente. 


\section{Pre-requisitos para el aprendizaje de la lectura y la escritura}

Según Núñez \& Santamarina (2014), manifiestan los siguientes prerrequisitos como factores claves que ayudaran al desarrollo académico y personal del niño durante su crecimiento;

1. Desarrollo de la motricidad: Todas las habilidades motrices y de orientación espacial y temporal son fundamentales para que el estudiante logre un adecuado inicio del aprendizaje de la lectura y la escritura.

2. Procesos cognitivos: Son diversos conjuntos necesarios y que se debe dominar para lograr que los estudiantes puedan escribir y leer, sin dejar de lado que también dependerá del desarrollo cognitivo del mismo alumno en el momento de iniciar dicho aprendizaje.

3. Habilidades o destrezas orales de la lengua: El ser humano al momento de nacer se encuentra rodeado de sus seres queridos, utilizando el lenguaje oral para manifestarse y poder comunicarse, ayudando a que los bebes asimilen este tipo de comunicación y logren desarrollando esta habilidad, siendo relevante en la etapa de la Educación Inicial, concibiendo como el instrumento primordial de aprendizaje, de regulación de la conducta y de manifestación de vivencias, sentimientos, ideas, emociones, etcétera.

4. Conciencia fonológica: las habilidades metalinguiísticas del lenguaje: es la capacidad para reflexionar y manipular los diversos compendios que constituyen el lenguaje (fonemas, palabras, estructura de las proposiciones) logrando reflexionar sobre su propio conocimiento

Al desarrollar las cuatro habilidades fundamentales como son el hablar, escuchar, leer y escribir, resultantes de la relación del código oral y escrito con las capacidades expresivas y comprensivas, que intervienen en el dominio de la lengua y que permiten que el individuo se comunique con claridad para expresar lo que piensa y siente.

\section{Metodologia}

Se realizará una observación objetiva mediante la cual con la aplicación de una ficha de observación se recolectaran datos eficaces con el fin de evidenciar ciertas falencias en los niveles de lectoescritura de los estudiantes que permitan identificar problemas concretos y proponer soluciones a los mismos, cuyo ficha de observación se fundamenta en los niveles de escritura y lectura que desarrollan los educandos a lo largo de su proceso educativo y en los cuales se presentan falencias que dañan su nivel cognitivo.

Es una investigación exploratoria, por su alcance, ya que no hay investigaciones previas. Es así como este "enfoque cuantitativo utiliza la lógica o razonamiento deductivo" (Hernández et al., 2014, pág. 19). Como también la recolección de datos se lo realizó por medio de una ficha de observación que fue elaborada para identificar las dificultades que 
tienen en el proceso, nivel y subnivel de lectoescritura la cual fue aplicada a un grupo de 79 estudiantes, mismo que ayudó para realizar la verificación de su confiabilidad para posteriormente usar el programa SPSS y determinar la validación de este.

El instrumento fue aplicado a los educandos del nivel medio de educación básica, donde consto con 23 ítems para quinto de básica, para sexto de básica 26 y para séptimo de básica fueron 30, todas ellas en relación en los procesos, niveles y subniveles de lectoescritura, utilizando una escala de valoración cualitativa de; no alcanza, domina y supera.

Para realizar la validación de la ficha de observación de cada año de básica, se utilizó la escala Alfa de Cronbach. Hernández et al. (2014) define como un instrumento con un alto porcentaje de confiabilidad debido a que sus parámetros de investigación a las variables están debidamente correlacionados lo que viabiliza la utilidad de cada ítem, logrando establecer la relación entre cada pregunta, así como en el objeto de estudio, de tal forma que al utilizar esta escala se trata de que se obtengan los valores máximos donde ayuden a validar el instrumento.

Hernández et al. (2014) afirma que la confiabilidad de un instrumento está relacionada con los resultados que se obtienen al aplican repetidas veces a una persona o grupo de personas un instrumento, que arroje resultados consistentes y coherentes. Según Hernández et al. (2014) "el tipo de coeficiente de fiabilidad mayormente reportado en la literatura es el coeficiente alfa también llamad, Alfa de Cronbach" (p.273). Este parámetro estadístico mide la fiabilidad de consistencia interna, grado en que las respuestas son consistentes a través de los ítems dentro de una medición”. Además, la fiabilidad de un instrumento varía de acuerdo con el número de ítems que contenga el instrumento de medición, entre más ítems tenga, su tendencia será mejor.

\section{Resultados}

La primera aplicación del cuestionario se realizó a una población de 79 estudiantes de quinto, sexto y séptimo año de escolaridad, con el cual se obtuvo resultados que nos permitieron ingresar las respuestas a una hoja de Excel y transformar, las respuestas a forma numérica, que posteriormente se ingresaron en el programa SPSS, que es un paquete estadístico considerado como un programa con gran difusión por todos los contenidos de análisis estadísticos para poder aplicar de una forma automática las fórmulas del Alfa de Cronbach que contiene las siguientes variantes (Hernández et al., 2014, p.208).

$$
\begin{gathered}
\alpha=\frac{K}{K-1}\left[1-\frac{W V i}{V t}\right] \\
\alpha=\text { Alfa de crombach }
\end{gathered}
$$




$$
\begin{aligned}
& \mathrm{k}=\text { Número de ítems } \\
& \mathrm{Vi}=\text { Varianza de cada Ítem } \\
& \mathrm{Vt}=\text { Varianza del total }
\end{aligned}
$$

Y que a su vez permiten la verificación de la ficha de observación en lo que tiene que ver con la confiabilidad, arrojando un resultado de 0.94 para quinto año con 23 ítems, 0.93 para sexto año con 26 ítems, 0.98 para Séptimo año con 30 ítems. Los resultados del cálculo del Alfa de Cronbach para el instrumento empleado se detallan en las siguientes graficas:

\section{Tabla 1}

Alfa de Cronbach quinto año

Escala: ANY

Resumen del proceso de casos
\begin{tabular}{|ll|r|r|}
\hline \multicolumn{1}{|c|}{} & \multicolumn{1}{c|}{$\%$} \\
\hline \hline Casos & Válido & 5 & 100,00 \\
& Excluido & 0 & , \\
& Total & 5 & 100,00 \\
\hline
\end{tabular}

Estadísticas de fiabilidad

\begin{tabular}{|r|r|}
\hline Alfa de Cronbach & N de elementos \\
\hline, 94 & 23 \\
\hline
\end{tabular}

\section{Tabla 2}

Alfa de Cronbach sexto año

\begin{tabular}{|c|c|c|c|}
\hline & & $N$ & $\%$ \\
\hline Casos & $\begin{array}{l}\text { Válido } \\
\text { Excluido } \\
\text { Total }\end{array}$ & $\begin{array}{l}5 \\
0 \\
5\end{array}$ & $\begin{array}{r}100,00 \\
, 00 \\
100,00\end{array}$ \\
\hline
\end{tabular}

Escala: ANY

Resumen del proceso de casos

Estadísticas de fiabilidad

\begin{tabular}{|r|r|}
\hline Alfa de Cronbach & N de elementos \\
\hline 93 & 26 \\
\hline
\end{tabular}

\section{Tabla 3}

Alfa de Cronbach séptimo año

Escala: ANY

Resumen del proceso de casos
\begin{tabular}{|ll|r|r|}
\hline \multicolumn{1}{|c|}{} & $N$ & \multicolumn{1}{c|}{$\%$} \\
\hline Casos & Válido & 5 & 100,00 \\
& Excluido & 0 &, 00 \\
& Total & 5 & 100,00 \\
\hline
\end{tabular}

Estadísticas de fiabilidad

\begin{tabular}{|r|r|}
\hline Alfa de Cronbach & N de elementos \\
\hline, 98 & 30 \\
\hline
\end{tabular}


Estos análisis utilizados demuestran que las fichas de observación planteadas son un medio confiable en la recolección de la información para el docente como instrumento de medición que ayude a terminar el proceso de lectoescritura en estudiantes de básica media.

Se adjunta las variables de estudio consideradas para la elaboración de las fichas de observación:

\section{Tabla 4}

Fichas de Observación

\begin{tabular}{|c|c|c|c|}
\hline & \multicolumn{3}{|c|}{ FICHAS DE OBSERVACION } \\
\hline N. & QUINTO AÑO & SEXTO AÑO & SEPTIMO AÑO \\
\hline 1 & LECTOESCRITURA & LECTOESCRITURA & LECTOESCRITURA \\
\hline & Historia Lectora & Historia Lectora & Historia Lectora \\
\hline 2 & Fase Lectora & $\begin{array}{l}\text { Historia Lectora sintetiza } \\
\text { información }\end{array}$ & $\begin{array}{l}\text { Historia Lectora resuelve } \\
\text { problemas }\end{array}$ \\
\hline 3 & Fase Escritora & Fase Lectora & Fase Lectora \\
\hline 4 & Fase Lectoescritora & Fase Escritora & Fase Escritora \\
\hline 5 & $\begin{array}{l}\text { LECTURA } \\
\text { Conciencia Fonológica } \\
\text { Conciencia silábica }\end{array}$ & Fase Lectoescritora & Fase Lectoescritora \\
\hline 6 & Conciencia Fonológica & LECTURA & LECTURA \\
\hline & Conciencia intra silábica & $\begin{array}{l}\text { Conciencia Fonológica } \\
\text { Conciencia silábica }\end{array}$ & $\begin{array}{l}\text { Conciencia Fonológica } \\
\text { Conciencia silábica }\end{array}$ \\
\hline 7 & $\begin{array}{l}\text { Conciencia Fonológica } \\
\text { Fonémica }\end{array}$ & $\begin{array}{l}\text { Conciencia Fonológica } \\
\text { Conciencia intra silábica }\end{array}$ & $\begin{array}{l}\text { Conciencia Fonológica } \\
\text { Conciencia intra silábica }\end{array}$ \\
\hline 8 & $\begin{array}{l}\text { LECTURA } \\
\text { Decodificación Primaria } \\
\text { Contextualización }\end{array}$ & $\begin{array}{l}\text { Conciencia Fonológica } \\
\text { Fonémica pronunciación }\end{array}$ & $\begin{array}{l}\text { Conciencia Fonológica } \\
\text { Fonémica pronunciación } \\
\text { correcta }\end{array}$ \\
\hline 9 & $\begin{array}{l}\text { Decodificación Primaria } \\
\text { Sinonimia }\end{array}$ & $\begin{array}{l}\text { Conciencia Fonológica } \\
\text { Fonémica representación }\end{array}$ & $\begin{array}{l}\text { Conciencia Fonológica } \\
\text { Fonémica proyección e } \\
\text { introspección }\end{array}$ \\
\hline 10 & $\begin{array}{l}\text { Decodificación Primaria } \\
\text { Radicación }\end{array}$ & $\begin{array}{l}\text { LECTURA } \\
\text { Decodificación Primaria } \\
\text { Contextualización }\end{array}$ & $\begin{array}{l}\text { LECTURA } \\
\text { Decodificación Primaria } \\
\text { Contextualización }\end{array}$ \\
\hline 11 & $\begin{array}{l}\text { Decodificación Secundaria } \\
\text { Puntuación }\end{array}$ & $\begin{array}{l}\text { Decodificación Primaria } \\
\text { Sinonimia }\end{array}$ & $\begin{array}{l}\text { Decodificación Primaria } \\
\text { Sinonimia }\end{array}$ \\
\hline 12 & $\begin{array}{l}\text { Decodificación Secundaria } \\
\text { Puntuación y espacios }\end{array}$ & $\begin{array}{l}\text { Decodificación Primaria } \\
\text { Radicación significado }\end{array}$ & $\begin{array}{l}\text { Decodificación Primaria } \\
\text { Radicación }\end{array}$ \\
\hline 13 & $\begin{array}{l}\text { Decodificación Secundaria } \\
\text { Pronominalización }\end{array}$ & $\begin{array}{l}\text { Decodificación Primaria } \\
\text { Radicación verbos }\end{array}$ & $\begin{array}{l}\text { Decodificación Secundaria } \\
\text { Puntuación }\end{array}$ \\
\hline 14 & $\begin{array}{l}\text { Decodificación Secundaria } \\
\text { Cromatización }\end{array}$ & $\begin{array}{l}\text { Decodificación Secundaria } \\
\text { Puntuación } \\
\text { interrogación/exclamación }\end{array}$ & $\begin{array}{l}\text { LECTURA } \\
\text { Decodificación Secundaria } \\
\text { Pronominalización uso } \\
\text { pronombres }\end{array}$ \\
\hline
\end{tabular}




\section{Tabla 4}

Fichas de Observación (continuación)

\begin{tabular}{|c|c|c|c|}
\hline \multicolumn{4}{|c|}{ FICHAS DE OBSERVACION } \\
\hline N. & QUINTO AÑO & SEXTO AÑO & SEPTIMO AÑO \\
\hline \multirow[t]{2}{*}{15} & Decodificación & Decodificación Secundaria & LECTURA Decodificación \\
\hline & $\begin{array}{l}\text { Secundaria Inferencia } \\
\text { proposicional }\end{array}$ & Signos de Puntuación & $\begin{array}{l}\text { Secundaria Pronominalización } \\
\text { cambio de pronombres }\end{array}$ \\
\hline \multirow[t]{2}{*}{16} & LECTURA & Decodificación Secundaria & LECTURA \\
\hline & Decodificación terciaria & Pronominalización & $\begin{array}{l}\text { Decodificación Secundaria } \\
\text { Cromatización }\end{array}$ \\
\hline \multirow[t]{2}{*}{17} & ESCRITURA & LECTURA & Decodificación Secundaria \\
\hline & Garabateo sin control & $\begin{array}{l}\text { Decodificación Secundaria } \\
\text { Cromatización }\end{array}$ & Inferencia proposicional \\
\hline \multirow[t]{2}{*}{18} & Garabateo controlado & Decodificación Secundaria & LECTURA \\
\hline & & Inferencia proposicional & $\begin{array}{l}\text { Decodificación terciaria } \\
\text { morfología y sintaxis }\end{array}$ \\
\hline 19 & $\begin{array}{l}\text { Garabateo con nombre } \\
\text { y uso de puntuación }\end{array}$ & Decodificación terciaria & $\begin{array}{l}\text { Decodificación terciaria } \\
\text { inferencia de un texto }\end{array}$ \\
\hline \multirow[t]{2}{*}{20} & Garabateo con nombre & ESCRITURA & ESCRITURA \\
\hline & de símbolos & Garabateo sin control & $\begin{array}{l}\text { Garabateo sin control define tipo } \\
\text { de letra }\end{array}$ \\
\hline 21 & Alfabético & Garabateo controlado & $\begin{array}{l}\text { Garabateo sin control precisión al } \\
\text { escribir }\end{array}$ \\
\hline \multirow[t]{2}{*}{22} & Escritura de oraciones & Garabateo controlado en & ESCRITURA \\
\hline & & trazos & $\begin{array}{l}\text { Garabateo controlado direcciones } \\
\text { e inclinaciones }\end{array}$ \\
\hline \multirow[t]{2}{*}{23} & Escritura con dictados & ESCRITURA & Garabateo controlado trazo \\
\hline & & Garabateo con nombre & correcto \\
\hline \multicolumn{2}{|l|}{24} & $\begin{array}{l}\text { Alfabético fonema y } \\
\text { grafema }\end{array}$ & $\begin{array}{l}\text { Garabateo con nombre signos y } \\
\text { símbolos en texto }\end{array}$ \\
\hline \multicolumn{2}{|l|}{25} & Alfabéticos párrafos cortos & $\begin{array}{l}\text { Garabateo con nombre signos y } \\
\text { símbolos en párrafos }\end{array}$ \\
\hline \multirow[t]{2}{*}{26} & & Alfabético entiende dictados & ESCRITURA \\
\hline & & & Alfabético fonema y grafema \\
\hline \multicolumn{2}{|l|}{27} & & Alfabético con rasgos caligráficos \\
\hline \multirow[t]{2}{*}{28} & & & ESCRITURA \\
\hline & & & Escritura de refranes \\
\hline \multicolumn{3}{|l|}{29} & $\begin{array}{l}\text { Escritura con signos de } \\
\text { puntuación }\end{array}$ \\
\hline 30 & & & $\begin{array}{l}\text { Escritura y explicación de frases y } \\
\text { párrafos }\end{array}$ \\
\hline
\end{tabular}

\section{Conclusiones}

- Se determinan como instrumento tres fichas de observación que ayudan al docente a desarrollar el proceso de lectoescritura en estudiantes de básica media, o acorde a la edad poder evaluar el mismo.

- El instrumento de ficha de observación es considerado según el proceso, nivel y subniveles de la lectoescritura. 
- Para la elaboración de la ficha de observación se ha considerado a la lectura y escritura como bases para la adquisición del proceso de lectoescritura.

- Las fichas de observación logran adquirir un "Alfa de Cronbach" como parámetro estadístico fiable de consistencia interna, siendo instrumentos aplicables para conocer el proceso de lectoescritura en estudiantes de básica media.

\section{Referencias bibliográficas}

American Institutes for Research (AIR). (2019). Initial literacy in Latin America and the Caribbean: a systematic review. Revie, 2, 60-71. https://www.revie.gob.do/index.php/revie/article/view/28

Avila, L. (2017). La enseñanza de la lectoescritura en la Educación Primaria: reflexión desde las dificultades de aprendizaje. Atenas, 2, 7-14. Obtenido de http://atenas.umcc.cu/index.php/atenas/article/view/279

Bañales, Gerardo., Ahumada, Silza. \& Martínez, Ricardo. (2017). Investigaciones de la escritura en la Educación Básica en Chile. revisión de una década. Scielo, 1, 1926. Obtenido de https://scielo.conicyt.cl/pdf/rla/v56n1/0718-4883-rla-56-0100059.pdf

Begoña, Mañas \& Hernández, R. S. (2018). La actitud ante la innovación del profesorado para la instrucción de nuevas metodologías didácticas en el acceso lectoescritor. Dialnet, $\quad$ 2, 1000-1240. Obtenido de https://dialnet.unirioja.es/servlet/articulo?codigo=7013457

Farrach, G. (2016). Estrategias Metodológicas para fomentar la comprensión lectora. Ciencias de la Educación, 2, 5-19. Obtenido de https://lamjol.info/index.php/FAREM/article/view/3064/2813

Hernández Sampieri, R., Fernández, C., \& Baptista, M. (2014). Metodología de la investigación. México: McGraw-Hill / Interamericana Editores, S.A. De C.V.

Jiménez, M. d. (2012). Problemas de lectoescritura. Dialnet, 1, 2-11. Obtenido de file://C:/Users/Usuario/AppData/Local/Temp/Dialnet-

ProblemasDeLectoescritura-5170654.pdf

Gómez, J., Maldonado, F. \& Martínez, M. (2016). Proceso de Lectoescritura. Huellas de la Palabra, $1, \quad 8-18 . \quad$ Obtenido de file://C:/Users/Usuario/AppData/Local/Temp/332-337-1-PB.pdf 
Lema Ruíz, R. A. (2019). El aprestamiento a la lectoescritura en la educación preescolar. CONRADO | Revista pedagógica de la Universidad de Cienfuegos. Obtenido de http://scielo.sld.cu/pdf/rc/v15n66/1990-8644-rc-15-66-244.pdf

Martínez, Mayda., González, Lucia, \& León, Ana. (2016). Alternativa didáctica para motivar por la lectura a los escolares de educación primaria desde la biblioteca y otras instituciones de la localidad. Dialnet, 1, 20-27. Obtenido de file://C:/Users/Usuario/AppData/Local/Temp/Dialnet-

AlternativaDidacticaParaMotivarPorLaLecturaALosEsc-6133070.pdf

Meneses, A. (2015). Factores que deben ser tenidos en cuenta en el proceso de adquisición de la lectura alfabética. facultad de psicología de la universidad católica de Colombia, 1, 5-11. Obtenido de https://editorial.ucatolica.edu.co/index.php/actacolombiana-psicologia/article/view/610/627

Núñez Delgado, M. P., \& Santamarina Sancho, M. (2014). Prerrequisitos para el proceso de aprendizaje de la lectura y la escritura: conciencia y fonológica y destrezas orales de la lengua. Lengua y Habla, 72-92. Obtenido de https://www.redalyc.org/pdf/5119/511951374006.pdf

Páez, A. (2018). Docentes y padres en el proceso de aprendizaje de los estudiantes. Dialnet, $\quad 1, \quad 5-17 . \quad$ Obtenido de https://dialnet.unirioja.es/servlet/articulo?codigo=7276123

Rodríguez, C. (2015). La Lectoescritura en Educación Infantil: Actividades para mejorar su desarrollo en el aula. Universidad de Valladolid, 2, 58-68. Obtenido de https://uvadoc.uva.es/bitstream/handle/10324/14586/TFG-

G1378.pdf;jsessionid=F3D28661732C870A19909E9496963257? sequence=1

Rosalia Montealegre, L. F. (2016). Desarrollo de la lectoescritura: adquisición y dominio1. Acta Colombiana de Psicología, 1-17. Obtenido de https://www.redalyc.org/pdf/798/79890103.pdf

Riera, S., Alvarez, T. \& García, S. (2015). Nuevo Marco para la Producción de Textos. Didáctica de Lengua y Literatura, 1, 12-36. Obtenido de https://core.ac.uk/download/pdf/38834077.pdf

Tamayo, S. (2017). La dislexia y las dificultades en la adquisición de la lectoescritura. Profesorado, 1, 8-11. https://www.redalyc.org/pdf/567/56750681021.pdf

Toledo Lenin, Muñoz, Sandra. \& Reyes, Edith. (2018). Técnicas lúdicas en el aprendizaje de la lectoescritura. espirales, 1, 5-18. Obtenido de file:///C:/Users/Usuario/AppData/Local/Temp/388-1229-1-PB.pdf 
El artículo que se publica es de exclusiva responsabilidad de los autores y no necesariamente reflejan el pensamiento de la Revista Conciencia Digital.

\section{Ciencia}

El artículo queda en propiedad de la revista y, por tanto, su publicación parcial y/o total en otro medio tiene que ser autorizado por el director de la Revista Conciencia Digital.
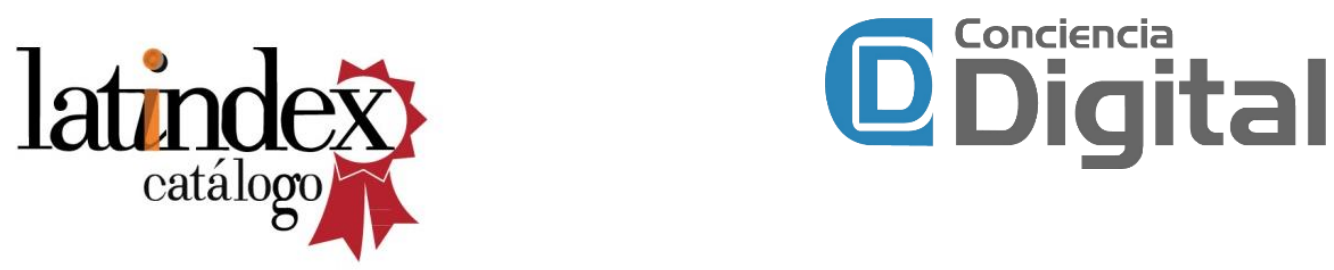

Indexaciones

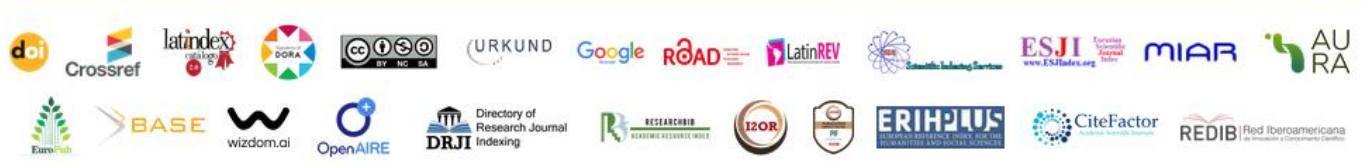

